\title{
Validation of patient knowledge questionnaire for patients with diabetes mellitus and hyperlipidemia
}

\author{
Ginanjar Zukhruf Saputri ${ }^{* 1}$, Haafizah Dania ${ }^{1}$, Imaniar Noor Faridah ${ }^{1}$, \\ Faiza Afra Chusnuni ${ }^{2}$ \\ ${ }^{1}$ Faculty of Pharmacy Universitas Ahmad Dahlan \\ Jl Prof. Dr. Soepomo S.H,Yogyakarta
}

Reviewed: 05-02-2018

Accepted: 02-11-2018

\begin{abstract}
The prevalence of Diabetes Mellitus (DM) with hyperlipidemia in Indonesia has shown an increase. Both of these diseases pose a risk of cardiovascular complications. DM patients with hyperlipidemia require proper management to control their blood glucose, total cholesterol, and LDL levels. Knowledge is one of the important factors in improving the adherence to therapy and the quality of life of DM-hyperlipidemia patients, especially in maintaining blood glucose and total cholesterol levels. This study aimed to develop a patient knowledge questionnaire for patients with DM-hyperlipidemia. The study used a cross-sectional method. The inclusion criteria were patients aged 18-70 years old and diagnosed with DM-Hyperlipidemia who received at least one oral antidiabetic and oral anti-cholesterol drug. The questionnaire items were developed based on the therapy guidelines and previous research and validated according to the opinion of scientific experts in DM and clinical psychologists. The pilot test included 10 healthy patients and 10 eligible DMhyperlipidemia patients. The questionnaire was then validated by interviewing $30 \mathrm{DM}$-Hyperlipidemia patients who received therapy at the outpatient clinic of PKU Muhammadiyah Hospital in Yogyakarta. The data obtained from this interview were analyzed in SPSS using the Pearson product-moment correlation coefficient and Cronbach's alpha to identify the reliability of the questionnaire. Based on the validation results, there were several invalid items, namely questions No. 9, 11, 12, 15, 16, and 17, which measured patient's knowledge of hyperlipidemia, medication, and general health. After omitting them, the re-test produced r-value> 0.3 and a Cronbach's alpha of 0.715 . The patient knowledge questionnaire for DM-Hyperlipidemia patients is valid and reliable for measuring the level of knowledge of patients with DM with dyslipidemia.
\end{abstract}

Keywords: DM-Hyperlipidemia, knowledge, validation, reliability

\footnotetext{
*Coressponding author:

Ginanjar Zukhruf Saputri

Faculty of Pharmacy, Universitas Ahmad Dahlan

J1 Prof. Dr. Soepomo S.H,Yogyakarta

Email: zukhruf.alparslan@gmail.com
} 


\section{INTRODUCTION}

In 2010, the International Database Federation (IDF) reported 10.4 million people diagnosed with Diabetes Mellitus in Indonesia, making this country with the fourth highest DM case after China, India, and America, and estimated this number to exceed 21 million people in 2025. Indonesia's Health Profile in 2012 showed that DM ranked as the sixth out of the ten major diseases in hospital outpatients in Indonesia (Kementrian Kesehatan RI, 2013).

DM patients and their families have an important role. Their understanding of DM management is significantly helpful in achieving better results. The crucial part of the management is controlling blood sugar and lipid levels. The comorbidity of dyslipidemia in DM indicates an increased risk of cardiovascular complications (PERKENI, 2015).

Previous research shows that DM-Hyperlipidemia management has to involve health professionals providing the education related to therapy, diet, exercise, blood sugar monitoring, foot injuries treatment, and management modification to improve the clinical outcomes and the quality of life of DM patients. Patients with DM and dyslipidemia need proper management to control blood sugar, total cholesterol, and LDL levels. In this management, patient knowledge is a fundamental factor that determines patients' ability to control their total blood glucose and cholesterol levels (Lai et al., 2012). Previous studies also affirm the strong relationship between patient knowledge and HbA1c control ( $\left.\mathrm{r}^{1 / 4}-0.61 ; \mathrm{P} 0.001\right)$, as well as the one between the knowledge of DM patients (without intervention) and blood glucose control. However, several studies show a negative correlation between knowledge and HbAlc (McPherson et al., 2008). Nevertheless, the research focusing on the knowledge and behavior of DM patients in India and Bangladesh states that patients who receive education and practice self-management of DM can control blood sugar levels better (Islam et al., 2014).

Although knowledge alone cannot guarantee any changes in patient behavior in improving the effectiveness of self-management (Islam et al., 2014; Stallwood, 2006; Norris, 2001), assessing the knowledge of DM-Hyperlipidemia patients of their disease and therapy management remains necessary. The results of this assessment can function as a parameter of the effectiveness of interventions, e.g., the provision of information and education or counseling. Lai et al. (2012) develop a reliable and valid questionnaire (reliability $=0.791$ ) to measure the knowledge of DM patients in Malaysia. This questionnaire has been widely used to assess the Knowledge, Attitude, and Practice (KAP) of DM patients in several countries like Nepal, India, and Malaysia (Upadhyay et al., 2008; Malathy et al., 2012). Focusing on KAP, Malathy et al., (2012) identify a significant change in the knowledge and behavior of DM patients in India (p <0.001). Meanwhile, Erku DA et al., (2017) use a knowledge questionnaire adapted from the Diabetes Knowledge Test by the Michigan Diabetes Research Training Centre and find the low level of knowledge of type 2 DM patients in Ethiopia with an average score of 11.54 .

The instrument used to measure patient knowledge is widely diverse. Therefore, it has to be adjusted through the process of validation and reliability measurement before being applied to a particular community. The development of this instrument in Indonesia is considered limited, especially for type $2 \mathrm{DM}$ patients with dyslipidemia and DM patients without complications. Considering the widely diverse comorbidities in DM, a particular knowledge questionnaire has to be developed for DM-Hyperlipidemia patients. Therefore, this research aimed to produce a reliable and valid instrument to measure the level of knowledge of DM-Hyperlipidemia patients.

\section{RESEARCH METHOD \\ Tools and Materials}

\section{Research Instrument: Patient Knowledge Questionnaire}

The patient knowledge questionnaire was prepared according to the DM-Hyperlipidemia guideline and previous studies. The DM-Hyperlipidemia knowledge questionnaire consisted of 20 questions that were divided into four (4) domains, namely Diabetes Mellitus, Hyperlipidemia, 
Treatment, and General health. This domain division was based on a previous study that developed patient knowledge questionnaire for patients with DM, cholesterol, and hypertension in Malaysia (McPherson et al., 2008).

The DM domain contained questions about DM, symptoms, blood sugar control, complications, and hypoglycemia management. The questions in the Hyperlipidemia domain focused on the symptoms of hypercholesterolemia, cholesterol level control, and complications. The Treatment domain asked about how to use DM drugs and anti-cholesterol drugs, treatment if side effects occur, and adherence to treatment therapy, while the general health domain consisted of questions about lifestyle, i.e., exercise, diet (mainly related to carbohydrate, sugar, and cholesterol diets), and smoking habit (McPherson et al., 2008). The questionnaire was then reviewed and used in a pilot test to interview ten (10) healthy respondents and ten (10) eligible DM patients.

The questions in the DM, Hyperlipidemia, and Treatment domains were designed with multiple choices with three (3) options or answers. For questions No. 1-15, score " 2 " was assigned to correct answer, while score "1" to wrong answer. As for the yes/no questions in No. 16-20 (general health domain), score " 1 " was given to "yes" and score " 0 " to "no". The level of patient knowledge was categorized into low (<56\%), moderate (56-75\%), and high (76-100\%) (Notoatmodjo, 2010; 2012).

\section{Research Procedure}

This research has been reviewed and approved by the Research Ethics Committee of Universitas Ahmad Dahlan with EC number of 011603042 . The questionnaire was prepared based on the results of the Focus Group Discussion (FGD) that involved several experts, namely pharmacists, doctors, and clinical psychologists. It was then reviewed and tested for validity and reliability based on DMHyperlipidemia expert judgment (i.e., internal medicine physicians and clinical psychologists). Afterward, it was subjected to a pilot test involving $10 \mathrm{DM}$-hyperlipidemia patients that met the inclusion criteria and 10 healthy respondents. The questionnaire validation included cross-sectional interviews with 30 DM-Hyperlipidemia patients who received outpatient care at PKU Muhammadiyah Hospital, Yogyakarta City.

The inclusion criteria were patients aged 18-65 years with a diagnosis of DM-Hyperlipidemia who received oral antidiabetic and oral anti-cholesterol drugs, showed cooperation, and had no conditions of illiteracy and hearing impairment. The primary data were obtained from patient interviews.

\section{Data Analysis}

The data analysis consisted of questionnaire validity test with the Pearson product-moment correlation and reliability test using the Cronbach's alpha analysis. The statistical analysis was performed in SPSS 21.

\section{RESULTS AND DISCUSSION}

This study aimed to develop a questionnaire as an instrument for measuring the knowledge of DM-Hyperlipidemia patients. Knowledge is one of the parameters in assessing the effectiveness of education (Islam et al., 2014; Stallwood, 2006; Norris, 2001). DM-hyperlipidemia patients need education related to disease management, drug administration, side effects treatment, exercise, and lifestyle management.

The demographic characteristics of the DM-Hyperlipidemia patients are presented in Table I. A total of 30 DM-Hyperlipidemia patients had completed the patient knowledge questionnaire. Most of them were female $(63.3 \%)$ and married $(100 \%)$. The demography in this research is similar to the study conducted by McPherson et al.(2008). The majority of the patients worked (93.3\%) and received more than 9 years of general education (60\%). More than half of them were younger than 60 years old $(66.7 \%)$ and without a family history of DM $(56.7 \%)$.

The questionnaire validity test was conducted using the Pearson product-moment correlation. A questionnaire item was valid when the resulted $r$-count was larger than the $r$-table (i.e., 0.3). The 
results showed that there were several invalid items, namely questions No. 9, 11, 12, 15, 16, and 17 ( $r$ count $<0.3$ ) (Table II).

The invalid questions were about knowledge of dyslipidemia (Hyperlipidemia domain), how to use cholesterol drugs and oral antidiabetic drugs (Treatment domain), and comprehension of sugar consumption and carbohydrate uptake (General Health domain). These results showed the lack of patient understanding of oral antidiabetic and oral anti-cholesterol drug administration. The ability of patients to distinguish sugar (glucose) and carbohydrates was also a problem when answering the questions. Some questions were written in relatively easy interrogative sentences that resulted in uniform answers, reducing the validity of the questionnaire. For instance, the statistical analysis in SPSS for question No. 16 did not yield $r$-count because the answers of the respondents were uniform. The invalid items were removed, and the questionnaire was re-tested for validity. The second validity test results are presented in Table III.

Table I. The demographic characteristics of respondents in the questionnaire validation

\begin{tabular}{|c|c|c|}
\hline Demographic Characteristics & $\begin{array}{c}\mathbf{N} \\
(\mathbf{\Sigma 3 0})\end{array}$ & Percentage / Mean \pm SD \\
\hline \multicolumn{3}{|l|}{ Sex } \\
\hline Female & 19 & $63.3 \%$ \\
\hline Male & 11 & $36.7 \%$ \\
\hline \multicolumn{3}{|l|}{ Marital Status } \\
\hline Married & 30 & $100 \%$ \\
\hline Not married & - & - \\
\hline \multicolumn{3}{|l|}{ Age } \\
\hline$<60$ years old & 20 & $66.7 \%$ \\
\hline$\geq 60$ years old & 10 & $33.3 \%$ \\
\hline \multicolumn{3}{|l|}{ Education } \\
\hline Education $<9$ years & 12 & $40.0 \%$ \\
\hline Education $>9$ years & 18 & $60.0 \%$ \\
\hline \multicolumn{3}{|l|}{ Employment } \\
\hline Employed & 28 & $93.3 \%$ \\
\hline Unemployed & 2 & $6.7 \%$ \\
\hline \multicolumn{3}{|l|}{ Family History of DM } \\
\hline Yes & 13 & $43.3 \%$ \\
\hline No & 17 & $56.7 \%$ \\
\hline
\end{tabular}


Table II. The validity test results of the patient knowledge questionnaire for DM-Hyperlipidemia Patients

\begin{tabular}{|c|c|c|c|c|}
\hline No & Question Items & $r$-count & $r$-table & Criteria \\
\hline \multicolumn{5}{|c|}{ Diabetes Mellitus Domain } \\
\hline 1 & $\begin{array}{l}\text { What is the normal range of random blood sugar } \\
\text { level? }\end{array}$ & 0.494 & 0.3061 & Valid \\
\hline 2 & $\begin{array}{l}\text { Which of the following options are the signs } \\
\text { and symptoms of DM? }\end{array}$ & 0.367 & 0.3061 & Valid \\
\hline 3 & $\begin{array}{l}\text { Which of the following options can lead to an } \\
\text { increase in blood sugar level? }\end{array}$ & 0.332 & 0.3061 & Valid \\
\hline 4 & $\begin{array}{l}\text { Which of the following options are the } \\
\text { complications of DM? }\end{array}$ & 0.379 & 0.3061 & Valid \\
\hline 5 & What do you know about hypoglycemia? & 0.516 & 0.3061 & Valid \\
\hline 6 & $\begin{array}{l}\text { What are the signs and symptoms of } \\
\text { hypoglycemia? }\end{array}$ & 0.747 & 0.3061 & Valid \\
\hline \multicolumn{5}{|c|}{ Hyperlipidemia Domain } \\
\hline 7 & $\begin{array}{l}\text { How is someone diagnosed as experiencing } \\
\text { hypercholesterolemia? }\end{array}$ & 0.357 & 0.3061 & Valid \\
\hline 8 & $\begin{array}{l}\text { Which of the following options are the signs } \\
\text { and symptoms of hypercholesterolemia? }\end{array}$ & 0.716 & 0.3061 & Valid \\
\hline 9 & $\begin{array}{l}\text { Which of the following options are the cause of } \\
\text { hypercholesterolemia? }\end{array}$ & - & 0.3061 & Invalid \\
\hline 10 & $\begin{array}{l}\text { Which of the following options are the } \\
\text { complications of hypercholesterolemia? }\end{array}$ & 0.607 & 0.3061 & Valid \\
\hline \multicolumn{5}{|c|}{ Treatment Domain } \\
\hline 11 & $\begin{array}{l}\text { Why do patients have to take DM medication } \\
\text { routinely? }\end{array}$ & 0.154 & 0.3061 & Invalid \\
\hline 12 & How is the right use of cholesterol medication? & 0.084 & 0.3061 & Invalid \\
\hline 13 & $\begin{array}{l}\text { Which of the following options are the } \\
\text { examples of side effects that often occur from } \\
\text { taking DM medication? }\end{array}$ & 0.662 & 0.3061 & Valid \\
\hline 14 & $\begin{array}{l}\text { How do you treat the side effects of DM } \\
\text { medication? }\end{array}$ & 0.643 & 0.3061 & Valid \\
\hline 15 & When is the right time to take metformin? & 0.030 & 0.3061 & Invalid \\
\hline \multicolumn{5}{|c|}{ General Health Domain } \\
\hline 16 & Smoking can increase the risk of heart disease & - & 0.3061 & Invalid \\
\hline 17 & I feel weak after consuming white sugar & 0.094 & 0.3061 & Invalid \\
\hline 18 & $\begin{array}{l}\text { Vegetable oil (e.g., olive oil, palm oil) does not } \\
\text { contain cholesterol, so it is safe if consumed in } \\
\text { large quantities. }\end{array}$ & 0.576 & 0.3061 & Valid \\
\hline 19 & $\begin{array}{l}\text { Exercise for } 30 \text { minutes per week is enough to } \\
\text { reduce the risk of coronary heart disease }\end{array}$ & 0.337 & 0.3061 & Valid \\
\hline 20 & $\begin{array}{l}\text { DM patients can consume fruits such as } \\
\text { bananas, papaya, oranges, and watermelons at } \\
\text { will. }\end{array}$ & 0.516 & 0.3061 & Valid \\
\hline
\end{tabular}


Table III. The second validity test results of the patient knowledge questionnaire for dm-hyperlipidemia patients

\begin{tabular}{lcccccc}
\hline No & $\begin{array}{c}\text { Questionnaire } \\
\text { Items }\end{array}$ & $\begin{array}{l}\text { Corrected Item- } \\
\text { Total Correlation }\end{array}$ & $\begin{array}{l}\text { Cronbach's } \\
\text { Alpha if Item } \\
\text { Deleted }\end{array}$ & $\boldsymbol{r}$-count & $\boldsymbol{r}$-table & Criteria \\
\hline 1 & Question 1 & 0.443 & 0.698 & 0.494 & 0.3061 & Valid \\
2 & Question 2 & 0.319 & 0.711 & 0.367 & 0.3061 & Valid \\
3 & Question 3 & 0.319 & 0.714 & 0.332 & 0.3061 & Valid \\
4 & Question 4 & 0.338 & 0.707 & 0.379 & 0.3061 & Valid \\
5 & Question 5 & 0.485 & 0.696 & 0.516 & 0.3061 & Valid \\
6 & Question 6 & 0.729 & 0.684 & 0.747 & 0.3061 & Valid \\
7 & Question 7 & 0.268 & 0.710 & 0.357 & 0.3061 & Valid \\
8 & Question 8 & 0.700 & 0.688 & 0.716 & 0.3061 & Valid \\
9 & Question 10 & 0.586 & 0.694 & 0.607 & 0.3061 & Valid \\
10 & Question 13 & 0.623 & 0.689 & 0.662 & 0.3061 & Valid \\
11 & Question 14 & 0.617 & 0.688 & 0.643 & 0.3061 & Valid \\
12 & Question 18 & 0.544 & 0.696 & 0.576 & 0.3061 & Valid \\
13 & Question 19 & 0.284 & 0.708 & 0.337 & 0.3061 & Valid \\
14 & Question 20 & 0.482 & 0.698 & 0.516 & 0.3061 & Valid \\
\hline
\end{tabular}

The results of the second validity test showed that the $r$-count of each questionnaire item was greater than 0.3 , indicating a valid patient knowledge questionnaire for further use on DMhyperlipidemia patients.

The reliability of the patient knowledge questionnaire, consisting of 20 items, was examined using the Cronbach's alpha analysis. The test results showed a Cronbach's alpha of 0.699. After the invalid items, i.e., questions No. 9, 11, 12, 15, 16, and 17, were omitted, the Cronbach's alpha of the second reliability test increased to 0.715. Since a questionnaire is categorized as reliable when the Cronbach's alpha is higher than 0.7, the patient knowledge questionnaire for DMHyperlipidemia patients developed in this research is, therefore, reliable. This finding is in line with Lai et al. (2012), which develop a knowledge-measuring instrument in Malaysia with a Cronbach's alpha of 0.791. Even though the Cronbach's alpha of this research is lower than the one in Lai et al.(2012), it is still greater than 0.7.

The level of knowledge of the DM-Hyperlipidemia patients is described in Table IV. The results showed that the majority of the patients had a high level of knowledge (86.7\%). Most of the patients aged $<60$ years had a high knowledge of DM-Hyperlipidemia. This finding is in line with McPherson et al. (2008), which affirm that patients aged $>65$ years old have a lower level of knowledge than the ones aged $<65$ years old. The average score of each domain is summarized in Table V.

Table IV. The level of knowledge of the DM-Hyperlipidemia patients

\begin{tabular}{cc}
\hline Levels of Knowledge & $\mathbf{N}(\%)$ \\
\hline Low & $1(3.3 \%)$ \\
Medium & $3(10 \%)$ \\
High & $26(86.7 \%)$ \\
\hline
\end{tabular}


Table V. The scores of the domains in the patient knowledge questionnaire for DMHyperlipidemia patients

\begin{tabular}{ccc}
\hline Domains & Mean \pm SD & Max. Score \\
\hline Diabetes Mellitus & $10.3 \pm 1.56$ & 12 \\
Hyperlipidemia & $5.4 \pm 1.00$ & 6 \\
Treatment & $3.13 \pm 0.97$ & 4 \\
General Health & $4.7 \pm 1.080$ & 6 \\
\hline
\end{tabular}

The patient knowledge questionnaire was designed with four (4) domains according to Lai et al.(2012) that developed a questionnaire for measuring the knowledge of DM-CholesterolHypertension patients. Some questionnaire items referred to and were translated from the questionnaire (McPherson et al., 2008). The average scores of the Diabetes Mellitus, Hyperlipidemia, Treatment, and General Health domains were $10.3 \pm 1.56,5.4 \pm 1.00,3.13 \pm 0.97$, and $4.7 \pm 1.080$, respectively. In the Diabetes Mellitus domain, the majority of the patients had a high score or, in other words, had good knowledge of the definition of DM, signs and symptoms, causes and risk factors, and complications from DM if not treated, as well as hypoglycemic side effects, signs, and symptoms.

In the Hyperlipidemia domain, there was one invalid item related to the etiology and risk factors for hyperlipidemia patients. This validity test result indicates the lack of patient's understanding regarding this matter. The patients do not understand the difference between total cholesterol, HDL, and LDL. This finding becomes an input to the provision of counseling and education for patients. Meanwhile, in the Treatment domain, there were 3 invalid questions concerning on the reasons for the routine use of DM medication, the use of anti-cholesterol drugs, and the right use of metformin. This condition shows that the patients still lack understanding of the routine use of DM medication and that some patients tend to stop the therapy when the clinical symptoms improve. Also, in the case of the comorbidity of hyperlipidemia in DM, patients are still not aware of the use of anti-cholesterol drugs (especially how to take simvastatin in the evening) and the principle of anti-cholesterol therapy (whether the anti-cholesterol medication has to be taken routinely or only when the signs and symptoms of hyperlipidemia appear). This finding becomes an input and concern for the pharmacists in providing education and counseling, especially related to disease management, drug therapy, and self-management and self-evaluation of DM-Hyperlipidemia patients. Diabetes Mellitus with dyslipidemia requires patients to understand the risk factors for cardiovascular complications. Therefore, pharmacists must have a special concern on this condition when providing the necessary education to DM-Hyperlipidemia patients.

Understanding the level of knowledge of DM-Hyperlipidemia patients, pharmacists are expected to be able to provide education and counseling related to each patient's problem as an effort to improve patient's adherence to therapy and quality of life. The patient knowledge questionnaire for DM-Hyperlipidemia is expected to be able to help pharmacists in health services to provide proper counseling and education.

The weakness of this study lies on the validity test because it does not compare the validity of the other knowledge-measuring questionnaires, such as in the cases of DHL (Diabetes, hypertension, and hyperlipidemia knowledge instrument) and MDKT (Michigan Diabetic knowledge tool). Also, it does not perform a second validation process due to the limited population of DM-Hyperlipidemia patients in the hospital. Therefore, further research in the development of a patient knowledgemeasuring instrument for DM-Hyperlipidemia becomes necessary.

\section{CONCLUSIONS}

The patient knowledge questionnaire for DM-Hyperlipidemia developed in this research is valid and reliable, as evident from the $r$-count $(>0.3)$ and the Cronbach's alpha $(0.715 ;>0.7)$. A comprehension of the level of patient's knowledge of DM-Hyperlipidemia is expected to improve the counseling offered by pharmacists. Therefore, pharmacists can help the problems that the patients 
experience related to the disease and treatment, which, as a result, can improve the adherence to therapy and the quality of life of DM-Hyperlipidemia patients. In other words, further research is highly suggested to include pharmacist intervention to improve the knowledge of DM-Hyperlipidemia patients.

\section{ACKNOWLEDGMENT}

Authors would like to thank all DM-Hyperlipidemia patients who have participated in this study. We hope for your health. We would also like to express our gratitude to PKU Muhammadiyah Hospital in Yogyakarta City, along with the nurse and doctor team in the internal medicine department, for their permission and cooperation during this research. We would also like to acknowledge the pharmacy students in UAD for their assistance in the technicalities of our research.

\section{REFERENCES}

Erku D.A, Belachew S.A, Mekuria A.B, Haile K.T, Gebresillassie B.M, Tegegn H.g, Ayele AA., 2017. The role of community pharmacists in patient counseling and health education: a survey of their knowledge and level of involvement in relation to type 2 diabetes mellitus. Dove Press Journal, Integrated Pharmacy Research and Practice: 137-143.

Islam A.F, Chackrabarti R, Dirani M, Islam M.T, Ormsby G, Wahab M, Critchley, Finger RP, 2014. Knowledge, attitudes and practice of diabetes in rural Bangladesh: The Bangladesh Population Based Diabetes and Eye Study (BPDES). Plos One: October, 9(10): 1-11.

Kementerian Kesehatan RI. 2013. Jumlah Penderita Diabetes Indonesia Rangking ke-4 di Dunia. Jakarta: Kemenkes RI.

Lai P.S.M, Chua S.S, Tan C.H, Chan S.P, 2012. Validation of the diabetes, hypertension and hyperlipidemia (DHL) knowledge instrument in Malaysia. BMC Medical Research Methodology, 12:18.

Malathy R, Narmadha M.P, Ramesh S, Alvin J.M, Dinesh B.N, 2011. Effect of a diabetes counseling programme on knowledge, attitude and practice among diabetic patients in erode district of South India. Journal of Young Pharmacists,3(1): 65-72.

McPherson, M.L, Smith S.W, Powers A, Zuckerman I.H, 2008. Association between diabetes patients' knowledge about medications and their blood glucose control. Research in Social and Administrative Pharmacy, 4: 37-45.

Norris S.L, Engelbau M.M, Narayan K.M.V, 2001. Effectiveness of self-management training in type 2 diabetes. Diabetes Care, 24:561-587.

Notoatmodjo, S, 2010. Promosi Kesehatan dan Perilaku Kesehatan, Rineka Cipta.

Notoatmodjo, S, 2012. Promosi Kesehatan dan Perilaku Kesehatan, Rineka Cipta, Jakarta: 137-147.

Palaian S, Acharya L.D, Rao M, Shankar P, Nair NM, Nair NP, 2006. Knowledge, attitude and practice outcomes: Evaluating the impact of counseling in hospitalized diabetic patients in India. $P \& T$ Around the world, 31(7): 383-400.

PERKENI. 2015. Panduan Pengelolaan Dislipidemia. Jakarta:PERKENI.

Stallwood L. 2006. Relationship between caregiver knowledge and socioeconomic factors on glycemic outcomes of young children with diabetes. J Spec Pediatric Nursing, 11: 158-165.

Upadhyay D.K, Palaian S, Shankar P.R, Mishra P, 2008. Knowledge, attitude and practice about diabetes among diabetes patients in western Nepal. Rawal Medical Journal , January: 1-9. 